\title{
The Role of a Web Portal to Facilitate Higher Learning Institutions Students' Field Attachment in Tanzania
}

\author{
Erick R. Samwi ${ }^{1 *}$, Kisangiri Michael ${ }^{2}$, Sabine Moebs ${ }^{3}$
}

\author{
${ }^{1}$ Moshi Co-operative University (MoCU), Kilimanjaro, TANZANIA \\ ${ }^{2}$ The Nelson Mandela African Institution of Science and Technology (NM-AIST), Arusha, TANZANIA \\ ${ }^{3}$ Baden-Wuerttemberg Cooperative State University (DHBW- Heidenheim), Heidenheim, GERMANY \\ *Corresponding Author: erick.samwi@mocu.ac.tz
}

Citation: Samwi, E. R., Michael, K. and Moebs, S. (2020). The Role of a Web Portal to Facilitate Higher Learning Institutions Students' Field Attachment in Tanzania. Journal of Information Systems Engineering and Management, 5(4), em0130. https://doi.org/10.29333/jisem/9140

\section{ARTICLE INFO}

Published: 4 Nov. 2020

\begin{abstract}
One of the approaches applied by Higher Learning Institutions to equip students with the practical skills is through field attachment in relevant companies based on field of studies. There are so many challenges in the process of coordination and allocation of students to relevant companies including expenses in terms of time and resources due to prolonged process involved. A web-based portal was developed to address the challenges for Tanzanian context. The development approach based on Scrum framework was employed to allow users involvement. To ensure information completeness, mixed-methods approach including key informant interviews, observations and requirements workshop were applied for portal's requirements elicitation. The requirements determined from users were further used to guide initial interface designs which were then converted to clickable wireframe pages using pencil software. The prototype was sent to real users via email for testing and improvement suggestions before real portal development. Scrum development approach was employed where increments development progress were frequently inspected to detect undesirable variances. The portal was finally validated and tested for usability and indicated to have improved field attachment process and open doors for more collaboration between Higher Learning Institutions and companies. This study provides insight on the approach used to come up with the solution regarding current challenges. Moreover, the contribution that the research based solution has brought to the students' field practices process is identified.
\end{abstract}

Keywords: Scrum, user-centered design, user-driven development, usability evaluation

\section{INTRODUCTION}

Field attachment refers to a practical subject done by Higher Learning Institutions (HLIs) students in companies or organizations which are relevant to their field of studies (Abdullah et al., 2017). The major aim of field attachment is to equip students with practical skills in their field of studies. In Tanzania, field attachment is mandatory and HLIs are responsible for monitoring students' performance through close follow-up in companies where students are allocated. Consequently, the allocation of students to relevant companies and coordination is becoming challenging with an increase in enrolment of students.

Currently, students manage their documents and search for companies manually. They submit applications to companies through email, post or by hand and wait for feedback. The coordinator is notified by students on acceptance or rejection for further supervision proceedings as indicated in Figure 1.

The process seems to be expensive for students, companies and Higher Learning Institutions in terms of time and resources. The motivation behind this study was to come up with the solution to curb the existing challenges.

Literatures proved the need for solution regarding allocation and coordination of HLIs students' field attachment. Furthermore, different approaches have been suggested and implemented befitting specific locations around the globe. The acceptance of the solutions was also reported to be a challenge in some cases as a result of ignoring users' involvement in the development process. Also, existing approaches do not create link to both stakeholders who are companies, students and HLIs thus not solving coordination issues.

Combination of techniques based on Scrum framework was applied in this study to avoid rejection of the product at final stages by involving users starting from early stages of development. All stakeholders (companies, students and HLIs) were involved in the study to enable understanding of the challenge at its entirety.

This study provides new approach towards addressing challenges associated with allocation and coordination of HLIs students' field attachment. It further expresses the contribution that the solution brought to process of equipping students with 


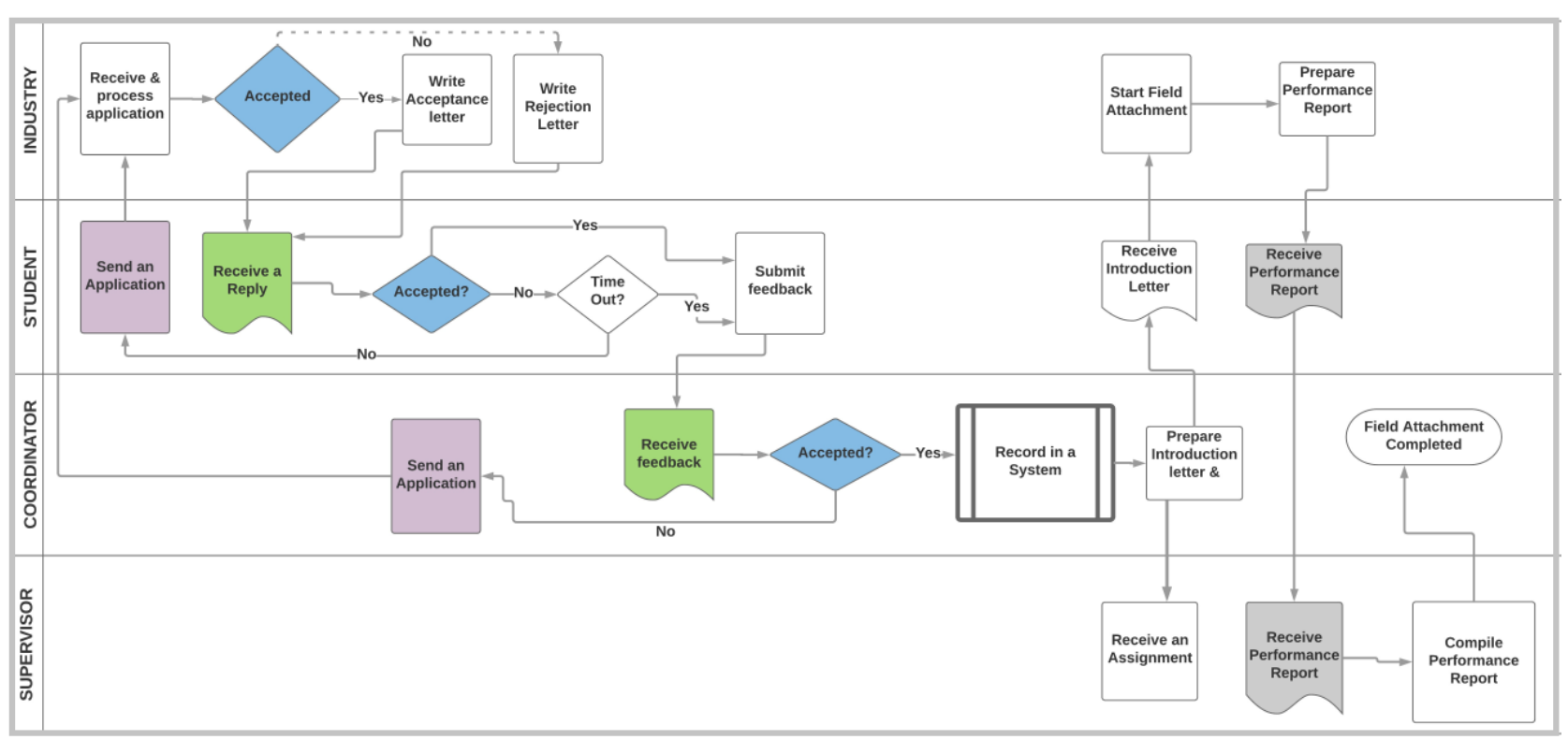

Figure 1. Current field attachment process model

practical experiences. The paper includes the description of the approaches applied, results and discussion of each approach, validation and conclusion.

\section{LITERATURE REVIEW}

\section{Related Works}

There are a number of articles that suggested different approaches to deal with challenges associated with the current practice. The approach suggested by (Abdullah et al., 2017) enable field attachment applicants to search and receive suggestions of best companies based on their study area and interests. This system has advantage of helping students to identify companies which are relevant to their study areas. However, the coordination as well as follow-up parts remain to be manual and challenging. Furthermore, suggestion made by (Tripathi, Singh \& Jaweria, 2018) is that of companies' access to student' resumes and interests. The approach helps to link students to potential companies but they do not consider students' choices and coordination by their respective HLIs. Another approach is to automatically notify students about suitable companies based on their registered preferences (Michael, 2016). Regardless of the fact that the system facilitates access of students to relevant companies, it does not solve the challenges associated with prolonged processes when it comes to follow-up and coordination done by respective HLIs.

The dual model of the Baden-Wuerttemberg Cooperative State University (DHBW-Heidenheim) is facilitated by the portal developed to link students to potential companies. The portal helped to open collaboration between the university and companies. The major limitation is that, by being a university specific portal, one company has to be linked to multiple portals to be able to receive profiles of students from different HLIs.

Efforts have been made in different Tanzanian universities to address field attachment challenges. Specifically, the College of Information and Communication Technology (CoICT) at University of Dar es Salaam came up with a web portal to facilitate allocation of supervisors and follow-up of their students when are in companies for field practices (PTMS, 2018). As this system can only facilitate the coordination part, it cannot be regarded as a solution to the current challenges of getting relevant companies. Moreover, the major challenges facing students and companies side are not addressed with this specific system.

Overall, these studies highlighted the need for a computerized system to facilitate the management and coordination of field attachment. Debate continues about the best strategies for addressing the challenge. This is because, the suggested approaches, have failed to address the challenges of linking both Higher Learning Institutions, students and organizations/companies which offer field practical trainings.

\section{Development Approaches}

Research conducted by (Shayo, Mwase \& Kissaka, 2017), reported the failure to adopt a system developed for university of Dar es Salaam regardless of the need of the computerized system for management and coordination of practical trainings. Lack of awareness of the system was revealed to be one of the reasons for the failure. This implies that, users were not involved and therefore the developed product had poor User Experience (UX). The life of software much depends on UX and therefore it a vital part to consider during software development (Harutyunyan \& Riehle, 2019). It is revealed that regardless of the benefits of the system, users tend to reject systems with poor UX (Sikorski, 2008). According to research done, users do not tolerate and only $16 \%$ will be willing to try applications with poor UX more than twice (Convertino \& Frishberg, 2017). 


\begin{tabular}{|c|c|c|c|}
\hline $\begin{array}{c}\text { As a <type of } \\
\text { user }\end{array}$ & $\begin{array}{c}\text { User } \\
\text { Story ID }\end{array}$ & $\begin{array}{c}\text { I want to <perform } \\
\text { some tasks }\end{array}$ & $\begin{array}{c}\text { so that I can <achieve } \\
\text { some goals }>\end{array}$ \\
\hline & & & \\
& & & \\
\hline
\end{tabular}

Figure 2. User stories template

User experience of a system is influenced by the techniques used to develop it. The study done by (Sy, 2007) to compare the usability of Agile and waterfall model designed software show that, Agile which is a collaborative user-centered design resulted in software with better usability. The main disadvantages of waterfall model are irreversible development phases and testing is done when software is complete and thus makes no room for users' complete involvement and flexibility to changes (Sommerville, 2011). The methodological approach used in this study is a mixed approach based on Scrum. Scrum is a framework which involves use of various processes and techniques to come up with product of the optimum value (Schwaber \& Sutherland, 2017). Scrum framework ensures the involvement of users in testing starting from the early development stages to continuously improve the product (Kieffer, Ghouti \& Macq, 2017). Moreover, involvement of users in all stages of development not only exposes design issues at the early stages of development but also positively affects the usability of a system (Myers \& Stylos, 2016).

\section{Validation Methods}

Although several methods exist to conduct usability evaluation, the suitability of a method depends on a scenario and type of software product (Paz \& Pow-sang, 2016). To allow major coverage of usability aspects, multiple methods were employed in this study. Quantitative usability metrics regarding effectiveness, efficiency, and satisfaction were established by applying user testing and questionnaires (Ashraf, Shabbir, Saba \& Mateen, 2017). User testing was preferred in this study because is the most useful usability evaluation method for the website since selected users execute some tasks while their performance and satisfaction are recorded (Mvungi \& Tossy, 2015).

\section{MATERIAL AND METHODS}

To optimize the chance of coming up with the best results, this study employed combination of techniques in requirements elicitation, design, implementation and usability evaluation.

\section{Requirements Elicitation}

Techniques for requirements elicitation do differ in characteristics and the quality of the information that they finally provide (Groves et al., 2009). In this study, mixed-method approach was employed considering the contribution of users' involvement, requirements information accuracy and completeness for the success of the end product (Pitts \& Browne, 2004). Techniques employed include key informant interviews, observations and requirements workshop.

The fact that key informant interviews allow open discussion of ideas, make it appropriate for collection of qualitative and descriptive information from respondents (Pact, 2014). With key informant interview, it was possible to gain clear understanding of the challenges and to realize new improvement ideas (Kumar, 1989). Furthermore, observation method helped to gain understanding of how users operate, inspirations and ideas for improvement and innovation (Kawulich, 2005). Not only that but also, a workshop was conducted to discuss and refine requirements with stakeholders. During the workshop, user stories were identified and formulated considering three basic components of user stories which are; description of the one who is representing the story, what is expected from the system and the criteria to accept a specific requirement (Lucassen, Dalpiaz, van der Werf, \& Brinkkemper, 2016). All stories were recorded on paper following the format as indicated in Figure 2.

\section{Design}

This study applied throw away prototype technique for the interface design. Interactive prototype that allowed navigation through pages were designed using pencil software and shared to five users of each group of stakeholders through email for testing and improvement suggestions. The prototype allowed users to have a touch of the final product before implementation so they could approve features and uncover any flaws at earlier stages (Houde \& Hill, 2007).

\section{Implementation}

The study employed collaborative user-centered development under Scrum framework to minimize errors and ensure greater usability (Maurya, Arai, Moriya, Arrighi, \& Mougenot, 2019). Scrum development approach allowed regular inspection of progress and acceptance testing of each increment (Karabulut \& Ergun, 2018). Increments were planned as a product release after every two weeks. For each increment (sprint) functional features were used to determine acceptance criteria which were investigated at the end of the task. Figure 3 is a framework of a Scrum development approach that was employed to develop a portal. 


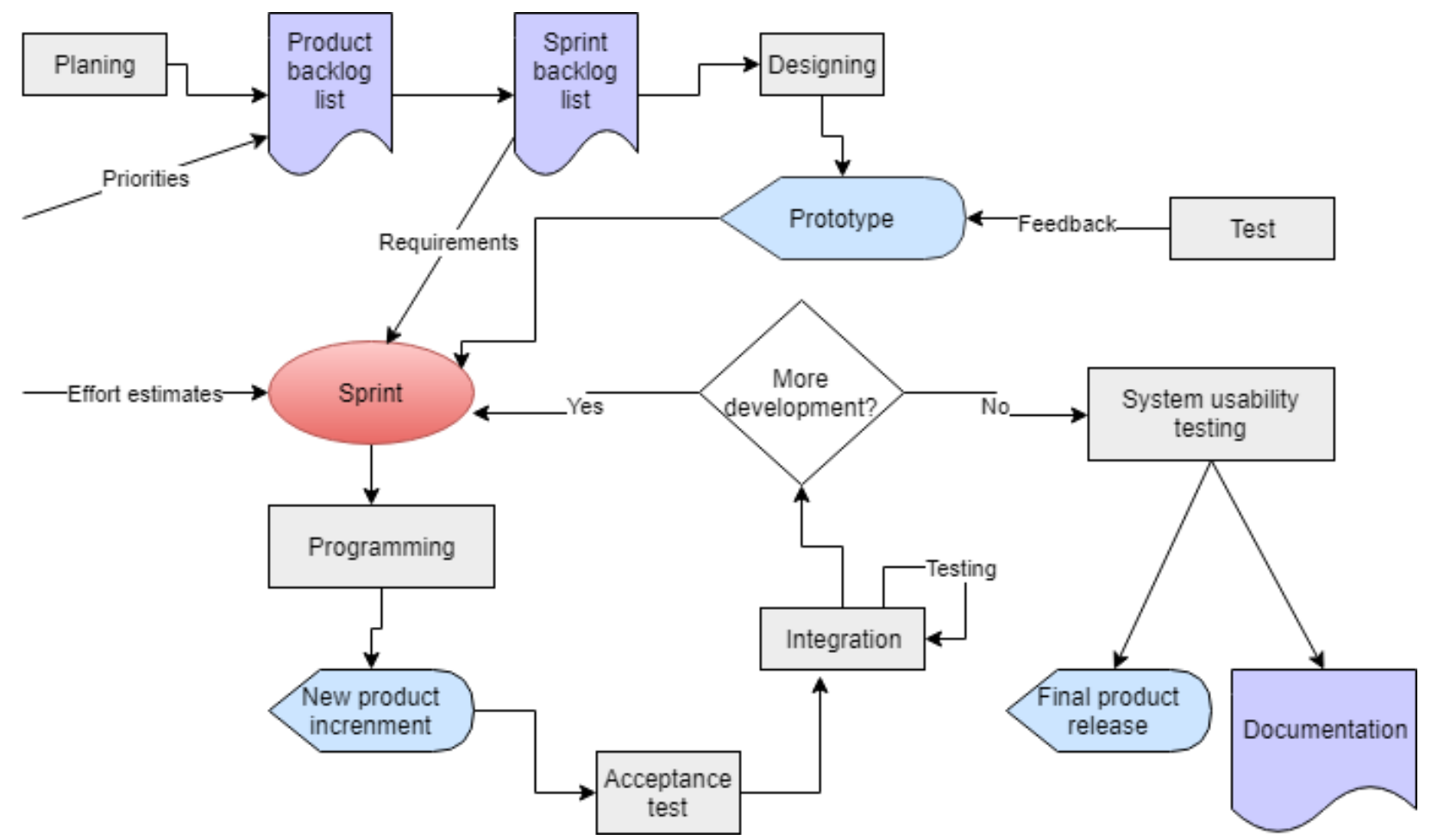

Figure 3. Scrum development approach

Table 1. Identified challenges facing each stakeholder

\begin{tabular}{lll}
\hline Stakeholders & & Higher Learning Institutions \\
\hline Students & Companies & Getting companies for field attachment \\
\hline Hard to search for relevant companies & Hard to find the right person & Missing allocation information \\
Applications feedback delay & Time to process manual applications & Hardship in manual documents processing \\
Irrelevant allocation & Expenses of communicating feedback & Costs associated with documents handling \\
Prolonged process & & Reports generation challenges \\
Searching expenses & & \\
\hline
\end{tabular}

\section{Usability Evaluation}

The evaluation involved 35 real users who were given task scenarios based on their roles as stakeholders in field attachment. The test plan composed of task scenarios for each group of users was prepared to guide the usability evaluation sessions. Selected users were introduced to the aim of the test session and then required to complete given task scenarios. Participants were observed while completing task scenarios to determine time spent on a task, ability to do a task correctly the first time and complete a goal. Users also responded to 3 different questionnaires:

Pre-test questionnaire, Test results can greatly be influenced by background and prior experience of test participants on using a computer (Hussain, Mkpojiogu, \& Hussain, 2015). Among others, the pre-test questionnaire was used to study the experience of participants on using the computer, their frequency on using computers, experience on any online application portal and frequency of using computers.

Post-task questionnaire, Post task questionnaire was prepared to get opinions of users on each task. Users involved in the testing were able to respond and give their experience on how did they find the process of completing a specific task using a developed portal.

The post-test questionnaire, The aim of the post-test questionnaire was to determine users' satisfaction with the entire system (Barnum, 2011). Participants were required to tell whether they agree, are neutral, disagree or strongly disagree with each of the given usability metrics.

Prior to usability evaluation, testing of the major functionalities was conducted to see if the developed portal (FAMS) is working properly and consistently (Hailpern \& Santhanam, 2002). This helped to ensure that usability test participants are not giving negative results due to functions that are not working well.

\section{RESULTS AND DISCUSSION}

The first approach was to examine the current practices and their challenges. Furthermore, improvement opportunities were identified and user requirements were determined to curb the identified challenges. The challenges that the stakeholders found to face with the current practice are as indicated in Table 1. 


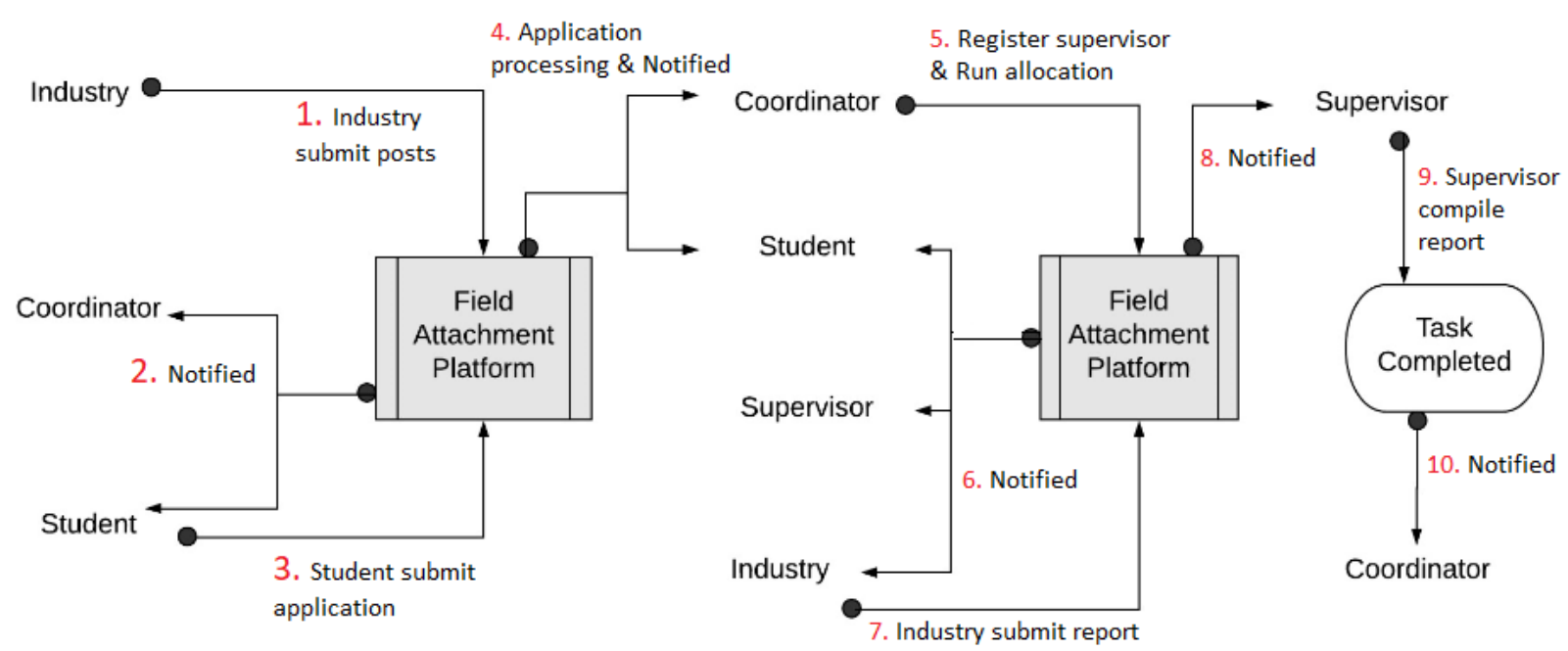

Figure 4. Conceptual workflow for field attachment system
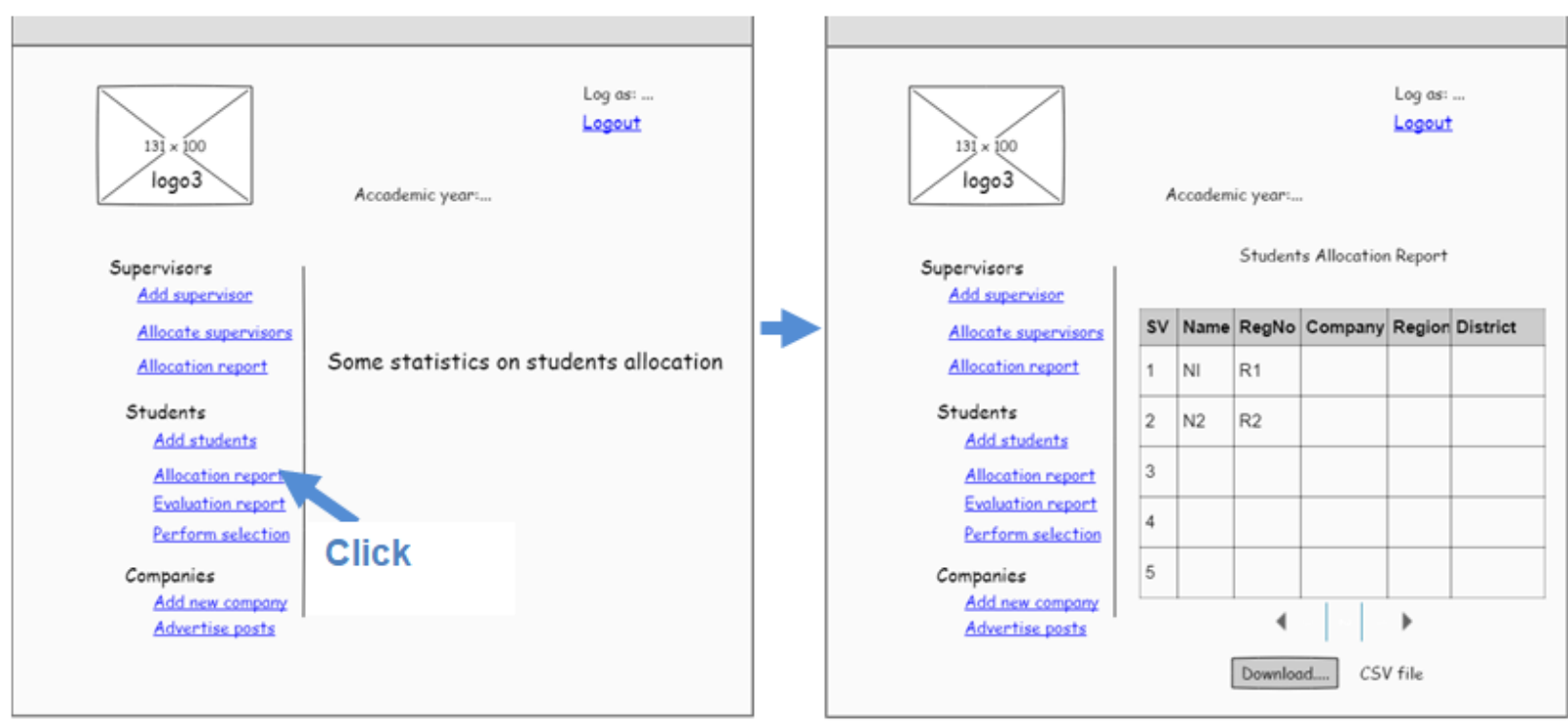

Figure 5. Final clickable wireframe pages

Together these findings regarding the challenges offered significant insights into the improvement of the current process. Based on the results, both functional and non-functional requirements for the proposed portal were identified. The results suggested linking all stakeholders using the same platform to allow collaboration between HLIs, students and companies. The resulting conceptual workflow that show what the portal will offer to users is as indicated in Figure 4.

User requirements were accommodated in the interface prototype design. The resulting User Interface (UI) after accommodating feedbacks from users who were involved in prototype testing is as indicated in Figure 5. The use of Graphical User Interface (GUI) in the final interface design was observed to have improved usability of the designed interface and users could easily realize where to find different functional features.

The final prototype resulted after accommodating feedbacks from design testing was then used to implement the portal. The developed portal allows companies to post requirements for field attachment, students to search and apply for relevant companies and HLIs to coordinate the process. Figure 6 is a sample conversion that was done from the final prototype to the working system interface.

The portal is intended to be used by four groups of users which are companies, HLIs students, coordinators and supervisors. Companies can register for an account through a registration link available on FAMS homepage. Furthermore, for the side of other stakeholders, registration is initiated by an administrator who is responsible for registering HLIs. After HLI being registered, a coordinator can use an account to register supervisors and add a list of eligible students in that specific HLI. Students can accomplish registration and open an account only after their registration numbers are uploaded into a system by a coordinator. Student's registration is done by selecting $\mathrm{HLI}$, registration number and fills other information like names and contacts. Figure 7 shows the home page interface on which user can navigate through a login link, new companies and students' registration links. 


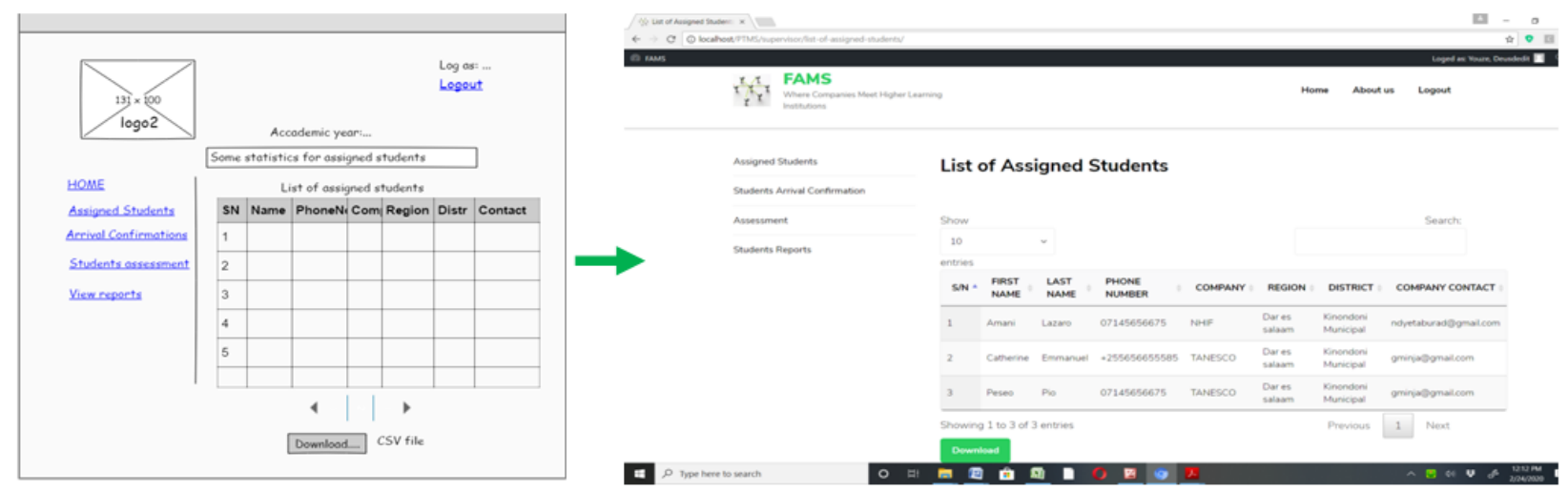

Figure 6. Supervisor's page

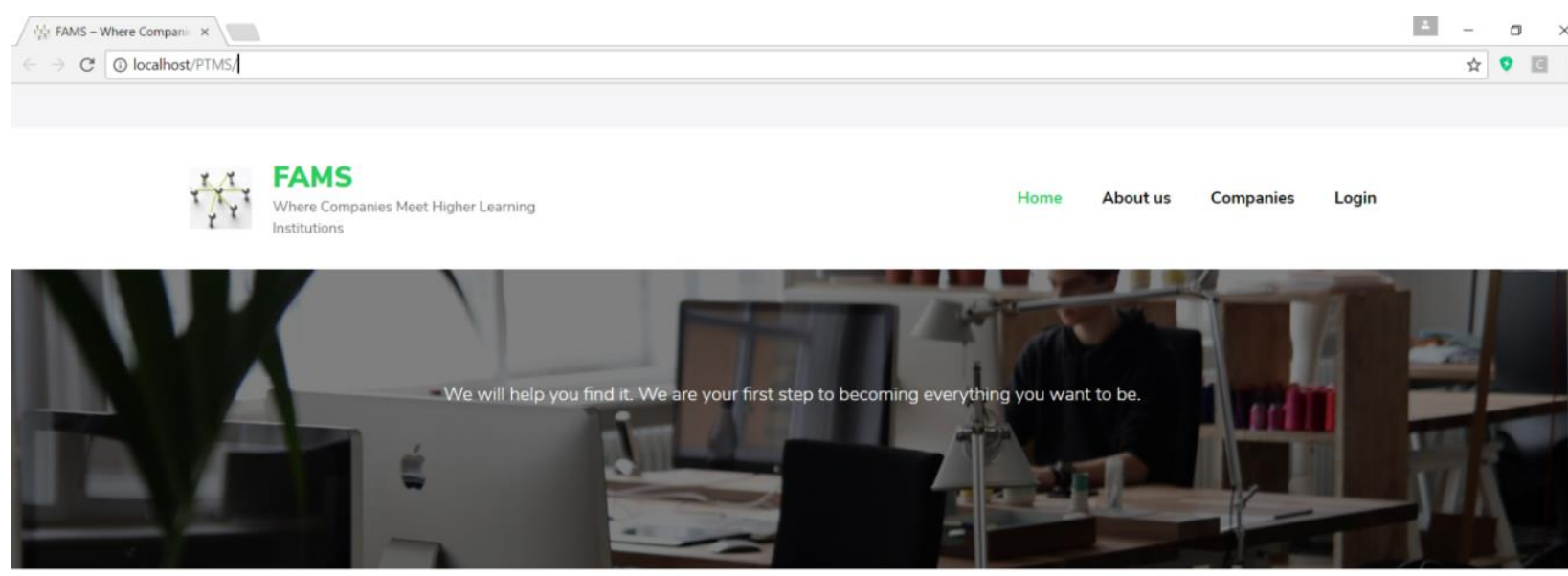

Company /Organization looking for trainees?

Student looking for field attachment?

Welcome to Field Attachment Management Portal!

Companies may advertise available posts to host students for field attachment

Students are able to search and apply to different companies.

Higher Learning Institutions can coordinate the processs, get reports and assess their students

0 Type here to search

○

○ 明回曾苗

Figure 7. Portal's home page

The evaluation for the usability of the running portal, Field Attachment Management System (FAMS) involved 20 HLI students, 5 coordinators from HLIs, 5 supervisors from HLIs and 5 companies' representatives. In a pilot test conducted prior to usability evaluation to determine the possible time that testers might take to accomplish a task scenario, participants were observed to be comfortable with a maximum of 5 minutes per task. The findings from the evaluation are as follows:

(i) All functions were tested and found that are working properly and consistently

The validation results confirmed the FAMS to have met the expected goal with correct behaviors regarding different inputs.

(ii) Test participants easily realized what the system is about and where to start

The first task scenario that users were given was to open the home page and tell what they could do with that page. All participants could easily realize that for as long as they are new users, they need first to go to a new user link for registration.

\section{(iii) Students were able to easily send an application to companies for field attachment}

A total of 17 students which is $85 \%$ percent of all students test participants were able to successfully send their applications in less than 5 minutes. This implies that it is easy for students to search for company, process and send an application.

\section{(iv) Students could easily find a list of companies based on their preferences and study area.}

All participants could easily recognize the use of the search icon while they were on the application page. The search icon gave them a pop up of a refined search option. With a refine search option, category of field study that a company offers, details on location and number of students the company can accommodate are displayed.

(v) Students could easily make a follow-up of their applications status 
Table 2. Users' responses on usability metrics of the entire system

\begin{tabular}{|c|c|c|c|c|c|}
\hline Usability Criteria & $\begin{array}{c}\text { Strongly } \\
\text { agree }\end{array}$ & Agree & Neutral & Disagree & $\begin{array}{l}\text { Strongly } \\
\text { disagree }\end{array}$ \\
\hline The system was easy to use & $71.43 \%$ & $28.57 \%$ & $0.00 \%$ & $0.00 \%$ & $0.00 \%$ \\
\hline I found the system unnecessarily complex & $0.00 \%$ & $0.00 \%$ & $0.00 \%$ & $42.86 \%$ & $57.14 \%$ \\
\hline I think I would need support from technician to use this system & $0.00 \%$ & $0.00 \%$ & $8.57 \%$ & $40.00 \%$ & $51.43 \%$ \\
\hline I found the flow of tasks in this system are well arranged & $62.86 \%$ & $37.14 \%$ & $0.00 \%$ & $0.00 \%$ & $0.00 \%$ \\
\hline There was too much inconsistency in this system & $0.00 \%$ & $0.00 \%$ & $0.00 \%$ & $20.00 \%$ & $80.00 \%$ \\
\hline The system is easy to learn & $80.00 \%$ & $17.14 \%$ & $2.86 \%$ & $0.00 \%$ & $0.00 \%$ \\
\hline The system is very cumbersome to use & $0.00 \% \%$ & $0.00 \%$ & $0.00 \%$ & $40.00 \%$ & $60.00 \%$ \\
\hline I needed to learn a lot of things before I could manage to use the system & $0.00 \%$ & $0.00 \%$ & $0.00 \%$ & $54.29 \%$ & $45.71 \%$ \\
\hline It was easy to find information I needed & $77.14 \%$ & $22.86 \%$ & $0.00 \%$ & $0.00 \%$ & $0.00 \%$ \\
\hline I enjoyed using the system interface & $74.29 \%$ & $25.71 \%$ & $0.00 \%$ & $0.00 \%$ & $0.00 \%$ \\
\hline Information provided by the system is easy to understand & $88.57 \%$ & $8.57 \%$ & $0.00 \%$ & $2.86 \%$ & $0.00 \%$ \\
\hline
\end{tabular}

Table 3. Test participants' success rates on task scenarios

\begin{tabular}{|c|c|c|c|c|}
\hline Task & Users category & Total participants & Succeeded Participants & Success rate \\
\hline Home page review & All & 35 & 35 & $100 \%$ \\
\hline Registration & Students & 20 & 20 & $100 \%$ \\
\hline Sending an application & Students & 20 & 20 & $100 \%$ \\
\hline Search by category & Students & 20 & 20 & $100 \%$ \\
\hline View application status & Students & 20 & 20 & $100 \%$ \\
\hline Reports submission & Students & 20 & 16 & $80 \%$ \\
\hline Adding eligible students & Coordinators & 5 & 5 & $100 \%$ \\
\hline Register new supervisors & Coordinators & 5 & 5 & $100 \%$ \\
\hline View allocation status & Coordinators & 5 & 5 & $100 \%$ \\
\hline Supervisors allocation & Coordinators & 5 & 5 & $100 \%$ \\
\hline Upload report templates & Coordinators & 5 & 2 & $40 \%$ \\
\hline View reports & Coordinators & 5 & 3 & $60 \%$ \\
\hline View allocated students & Supervisors & 5 & 5 & $100 \%$ \\
\hline View arrival declaration & Supervisors & 5 & 3 & $60 \%$ \\
\hline review students reports & Supervisors & 5 & 5 & $100 \%$ \\
\hline Student assessment & Supervisors & 5 & 5 & $100 \%$ \\
\hline Registration & Companies & 5 & 5 & $100 \%$ \\
\hline Post advertisement & Companies & 5 & 5 & $100 \%$ \\
\hline Advertise 2 field area & Companies & 5 & 5 & $100 \%$ \\
\hline Select students & Companies & 5 & 5 & $100 \%$ \\
\hline Students evaluation & Companies & 5 & 2 & $40 \%$ \\
\hline
\end{tabular}

Usability test results recorded regarding users' ability to find status information of their applications show that all participants could do a follow-up and send a confirmation note to the company. The result shows that $80 \%$ of participants were able to make follow-ups in less than 5 minutes.

\section{(vi) Companies could easily post the advertisement of field attachment posts}

It was found that all 5 participated users from companies were able to register into the system and post advertisements of field attachment posts. Furthermore, all were able to successfully post field attachment with full details in less than 5 minutes. A scenario where a single company has more than one branch was also tested for usability. The participants could add a branch for a registered company and successfully post an advertisement within 5 minutes.

\section{(vii) Companies could easily view applicants profiles}

Participants from companies were also asked to view information that will help them to make selection decisions out of the number of applications that they received. The results show that, all participants were able to view applicants' profiles and update the selection status in less than 5 minutes.

(viii) Field attachment coordinators were able to easily register lists of students and supervisors into a system and view allocation reports.

All 5 field attachment coordinators participated in testing successfully uploaded a list of eligible students, registered new supervisors and downloaded supervisors' allocation reports. The success was due to a reason that the information about the expected report was available in the system.

\section{(ix) Participants agreed that FAMS met usability criteria}

Usability evaluation participants were very positive regarding all the usability scenarios. Most of the participants strongly agreed on positive usability statements and strongly disagreed on counter usability statements. Table 2 presents the results of responses to the post-test questionnaire.

The overall success rate on test scenarios provided for usability evaluation shows that most of the tasks were accomplished by $100 \%$ of test participants consistently as indicated in Table 3 . 
Table 4. Benefits of the portal to each stakeholder

\begin{tabular}{lll}
\hline Stakeholders & & Higher Learning Institutions \\
\hline Students & Companies & Reliable allocation information base \\
\hline Easy access to relevant companies & Easy to process applications & Saves documents processing time \\
\hline Easy follow-up of applications & No costs in communicating feedback & No documents handling costs \\
\hline No searching and application costs & Easy to find a right person & Easy reports generation \\
\hline
\end{tabular}

Tasks with a low success rate and those which took participants more than 5 minutes to succeed were further analyzed to get reasons for bad performance. The reasons were observed to be lack of proper instruction and clear error message to enable correction of wrong inputs. Issues were corrected and left the portal with good usability.

As compared to similar systems, the developed portal is of benefit to both parties involved in students' field attachment. The benefits that the portal found to offer to both field attachment stakeholders are as per Table 4.

\section{CONCLUSION}

This study intended to address challenges in field attachment of Tanzanian HLI students by integrating features of major functions of all three stakeholders. The portal to integrate HLIs, companies and students was developed using a user-centered collaborative approach under Scrum framework to ensure full involvement of users and the right final product. Furthermore, usability evaluation was conducted by applying user testing and questionnaires techniques to determine the effectiveness, efficiency and satisfaction of users on using the developed portal.

A total of 35 participants from all groups of real users were involved in usability evaluation. Participants were observed while responding to task scenarios based on their roles to determine the time taken to complete a task, whether a user can complete his goal, do a task correctly, get help he might need and perform the task correctly the first time. Furthermore, participants gave their opinions, experience and suggestion for improvement on each task given. They also expressed their satisfaction by rating different features with regards to usability.

The involvement of users from the early stages of development helped to come up with a portal that works properly and consistently. Results show that the goal was met with correct behavior regarding different inputs. Moreover, all participants including those who were not involved in requirement determination and testing of the design were found to have managed to realize what the system is about. The high degree of acceptance and success to accomplish tasks correctly realized from this study confirms improvement in field attachment process. The improvement of field attachment process that this study has made is a result of the collaborative approach used to develop a portal and the unique feature of integrating functions of HLIs, students and companies.

\section{RECOMMENDATIONS}

Since this study had only focused on field attachment, further research is recommended to include more value addition features like analysis of feedback from companies to get information that can be used by HLIs in regular curriculum reviews. Some other additional features like internship and job finding can also be further researched for allowing more collaboration between companies and HLIs since HLIs are responsible for producing expatriates to work in companies. It is also recommended that further research should be carried out on HLIs which bear the responsibility to find and allocate students to field attachment to see whether there are any different needs.

\section{REFERENCES}

Abdullah, F., Seman, A. A., Majid, N. A., Abdul, N. M., Mustafa, M. and Sani, N. F. (2017). Web-based application of the internship management system. Journal of Computing Research and Innovation, 2(3), 46-51. https://crinn.conferencehunter.com

Ashraf, M., Shabbir, F., Saba, T. and Mateen, A. (2017). Usability of government websites. International Journal of Advanced Computer Science and Applications, 8(8), 163-167. https://doi.org/10.14569/ijacsa.2017.080821

Barnum, C. (2011). Usability Testing Essentials. Elsevier Inc. https://doi.org/10.1016/C2009-0-20478-8

Convertino, G. and Frishberg, N. (2017). Why agile teams fail without UX research. Communications of the ACM, 60(9), 35-37. https://doi.org/10.1145/3126156

Groves, R. M., Fowler, F. J., Couper, M., Lepkowski, J. M., Singer, E. and Tourangeau, R. (2009). Survey methodology (2nd ed.). New Jersey: Wiley.

Hailpern, B. and Santhanam, P. (2002). Software debugging, testing, and verification. IBM Systems Journal, 41(1), 4-12. https://doi.org/10.1147/sj.411.0004

Harutyunyan, N. and Riehle, D. (2019). User experience design in software product lines. Proceedings of the $52^{\text {nd }}$ Hawaii International Conference on System Sciences|2019, 6, 7503-7512. https://doi.org/10.24251/HICSS.2019.903 
Houde, S. and Hill, C. (2007). What do prototypes prototype? Handbook of human-computer interaction, $367-381$. https://doi.org/10.1016/b978-044481862-1/50082-0

Hussain, A., Mkpojiogu, E. O. C. and Hussain, Z. (2015). Usability evaluation of a web-based health awareness portal on smartphone devices using ISO 9241-11 model. Jurnal Teknologi, 77(4), 1-5. https://doi.org/10.11113/jt.v77.6035

Karabulut, A. T. and Ergun, E. (2018). A new way of management: A scrum management. International Journal of Commerce and Finance (Vol. 4). Retrieved from http://en.wikipedia.org/wiki/Scrum_

Kawulich, B. B. (2005). Participant observation as a data collection method. Forum Qualitative Sozialforschung / Forum: Qualitative Social Research, 6(2), Art. 43. https://doi.org/10.17169/FQS-6.2.466

Kieffer, S., Ghouti, A. and Macq, B. (2017). The agile UX development lifecycle: Combining formative usability and agile methods. In Proceedings of the 50th Hawaii International Conference on System Sciences (2017) (pp. 577-586). https://doi.org/10.24251/hicss.2017.070

Kumar, K. (1989). Conducting Key Informant Interviews in Developing Countries A.I.D. Program Design and Evaluation Methodology Report NO. 13. Retrieved from https://www.participatorymethods.org/sites/participatorymethods.org/files/conducting key informant interviews_kumar.pdf

Lucassen, G., Dalpiaz, F., van der Werf, J. M. E. M. and Brinkkemper, S. (2016). Improving agile requirements: The quality user story framework and tool. Requirements Engineering, 21(3), 383-403. https://doi.org/10.1007/s00766-016-0250-x

Maurya, S., Arai, K., Moriya, K., Arrighi, P. A. and Mougenot, C. (2019). A mixed reality tool for end-users participation in early creative design tasks. International Journal on Interactive Design and Manufacturing, 13(1), $163-182$. https://doi.org/10.1007/s12008-018-0499-z

Michael, O. S. (2016). Mobile-based SIWES placement recommendation system (A case study of mobile-based SIWES placement recommendation system (A case study of nigerian universities), (July), 0-7. https://doi.org/10.13140/RG.2.1.1433.4967

Mvungi, J. and Tossy, T. (2015). Usability evaluation methods and principles for the web. International Journal of Computer Science and Information Security, 13(7), 86-92. Retrieved from http://ijcsse.org/published/volume4/issue7/p1-V4I7.pdf

Myers, B. Y. B. A. and Stylos, J. (2016). Improving API usability. Communications of the ACM, 59(6), 62-69. https://doi.org/10.1145/2896587

Pact, I. (2014). Field guide for evaluation: How to develop an effective terms of reference results and measurement. Washington, DC: Author.

Paz, F. and Pow-sang, J. A. (2016). A systematic mapping review of usability evaluation methods for software development process. International Journal of Software Engineering and Its Applications, 10(1), 165-178. https://doi.org/10.14257/ijseia.2016.10.1.16

Pitts, M. G. and Browne, G. J. (2004). Stopping behavior of systems analysts during Information requirements elicitation. Journal of Management Information Systems, 21(1), 203-226. https://doi.org/10.2307/40398789

PTMS website. (n.d.). Retrieved on October 26, 2018 from http://41.86.176.15/index.php/ptms

Schwaber, K. and Sutherland, J. (2017). The scrum guide ${ }^{T M}$ the definitive guide to scrum: The rules of the game. Retrieved from https://www.scrumguides.org/docs/scrumguide/

Shayo, E., Mwase, C. and Kissaka, M. (2017). Barriers towards the adoption of a practical training management system at the university of Dar es Salaam. IST-Africa Week Conference. Retrieved from https://www.semanticscholar.org/paper/

Sikorski, M. (2008). HCl and the economics of user experience. In Law E.LC., Hvannberg E.T., Cockton G. (eds) Maturing Usability. Human-Computer Interaction Series. (pp. 318-343). London: Springer. https://doi.org/10.1007/978-1-84628-941-5_14

Sommerville, I. (2011). Ninth Edition. (M. Horton, M. Hirsch, M. Goldstein and C. Bell, Eds.) (9th ed.). Boston, Massachusetts 02116: Pearson Education, Inc.

Sy, D. (2007). Adapting usability investigations for agile user-centered design. Journal of Usability Studies, 2(3), 112-132. Retrived from http://uxpajournal.org/wp-content/uploads/pdf/JUS_Sy_May2007.pdf

Tripathi, R., Singh, R. and Jaweria, M. (2018). Campus recruitment and placement system. International Conference on Recent Innovations in Science and Engineering, 293-298. Retrieved from www.conferenceworld.in 